\title{
EDITORIAL
}

\section{Global Antimicrobial Stewardship: Challenges and Successes from Frontline Stewards}

Debra A. Goff · Michael J. Rybak

To view enhanced content go to www.infectiousdiseases-open.com

Received: September 4, 2015 / Published online: September 11, 2015

(C) The Author(s) 2015. This article is published with open access at Springerlink.com

\section{INTRODUCTION}

The current global overuse and misuse of antimicrobials requires an urgent international response. According to the 2014 World Health Organization (WHO) Antimicrobial Resistance Global Report on Surveillance, deaths per year due to antibiotic resistance are reported as high as 23,000 in the United States, 25,000 in the European Union, 38,000 in Thailand and 58,000 in India [1]. The WHO developed a Global Action Plan in May 2015 mandating member states to produce national strategic plans to combat antimicrobial resistance by establishing a global development and antibiotic stewardship framework [2]. Many countries have successfully implemented

D. A. Goff

Department of Pharmacy, The Ohio State University Wexner Medical Center, Columbus, OH, USA

\section{J. Rybak}

Anti-Infective Research Laboratory, Department of Pharmacy Practice, Eugene Applebaum College of Pharmacy and Health Sciences, Wayne State University, Detroit, MI, USA

\section{J. Rybak ( $ه)$}

Division of Infectious Diseases, School of Medicine, Wayne State University, Detroit, MI, USA e-mail: aa1592@wayne.edu antimicrobial stewardship programs in the hospital setting while several limited resource countries continue to struggle with getting stewardship programs up and running.

The art of antimicrobial stewardship (AMS) is an evolving discipline. The articles in this themed issue aim to provide the reader with an overview of successful antimicrobial stewardship programs from 6 different countries; the United States, United Kingdom, South Africa, Singapore, Australia, and Italy. The authors discuss the international role of pharmacists in AMS. Included in this issue are two studies from South Africa and Singapore and four reviews of stewardship efforts with a description of the pharmacist's role.

The issue starts with a study by Messina et al. from South Africa, a resource-limited country. This prospective multi-center pharmacist-driven study aimed to improve the "hangtime" of antibiotics defined as the time elapsed from the written antibiotic order to actual intravenous administration. Pharmacists from 33 hospitals evaluated and intervened on 32,985 patients over a 60 -week study period and significantly improved "hangtime compliance from $41.2 \%$ to $78.4 \%$. The success of this 
initiative by non-infectious disease pharmacists is partially attributed to the pharmacist project manager who coordinated and provided real-time data and feedback to the frontline pharmacists. The large number of patients and sustained efforts provides a successful ASP model for other countries especially those with limited resources.

The next study by Loo et al. from Singapore is a 3-year retrospective review evaluating the impact of ASP and outcomes of hospitalized patients with skin and skin soft tissue infections. Pharmacists made over 400 antimicrobial recommendations with an overall acceptance rate of $66.8 \%$. They demonstrated that ASP interventions were safe and reduced duration of therapy, length of stay and resulted in institutional cost savings. In contrast to South Africa, the pharmacists were ID trained and provided a two-stage prospective audit with immediate and concurrent feedback to the physicians. Their ASP model could be applied to a variety of healthcare settings worldwide.

The third paper by Cairns $\mathrm{K}$ et al. provides a comprehensive review of the role of pharmacists in antimicrobial stewardship (AMS) in Australia. The authors describe the recent incorporation of AMS into mandatory hospital accreditation standards and the release of the first national strategy on antimicrobial resistance. As there is not a "one-size fits all" model for AMS in Australia, they provide two different examples, one from a general hospital setting and one with specialized areas.

Trinh T. et al. provides the United States perspective for the role of AMS initiatives in the emergency department (ED). With over 142,000 visits to the $\mathrm{ED}$ for antibiotic-related adverse drug reactions, there is clearly a need for AMS. The authors describe the top three infection-related ED visits (urinary tract infections, skin and soft tissue infections and pneumonia) and provide ED AMS strategies. Support from ED practitioners is the first critical step to implement AMS in the ED.

The next paper by Gilchrist et al. describes AMS experience from the UK antimicrobial pharmacist perspective. Pharmacists were thrust into a key role in AMS in 2003 after the Department of Health infused significant funding to hospital pharmacies in England to improve the monitoring and control of anti-infectives. The authors provide documentation of the progress made by pharmacists working collaboratively with infectious diseases clinicians, microbiologists, and other healthcare professional helping to drive the AMS efforts in both primary and secondary care.

The final paper by Viale P. et al. reviews the literature on the topic carbapenem resistance in the setting of extended spectrum beta-lactamase resistance and the role of AMS. In addition, they describe the experience from an Italian University affiliated hospital multifaceted infection control and AMS program to reduce carbapenem-resistant enterobacteriaceae (CRE) bloodstream infections. The role of both ceftolozane/tazobactam and ceftazidime/ avibactam under a specific AMS aim is also described.

We have designed this issue to provide clinicians with the latest approaches to AMS from 6 different countries worldwide. Every prescriber should be an antibiotic steward. Pharmacists working in collaboration with physician colleagues have a key role in AMS and can be instrumental in initiating the behavior change necessary to bring about transformation change in antibiotic use. We are confident that this information will provide value to the steward and will start a movement 
to work together in the journey to implement effective AMS globally.

\section{ACKNOWLEDGMENTS}

No funding or sponsorship was received for the publication of this article. All named authors meet the International Committee of Medical Journal Editors (ICMJE) criteria for authorship for this manuscript, take responsibility for the integrity of the work as a whole, and have given final approval for the version to be published.

Disclosures. Debra Goff has nothing to disclose. Michael J. Rybak has been a speaker and/or consultant and obtained research support from Actavis, Cubist, and Theravance; speaker and/or consultant for Bayer, Durata, Novartis, The Medicines Company, and Sunovian; and obtained research and partial salary support from NIH R21 AI109266-01.

Open Access. This article is distributed under the terms of the Creative Commons Attribution-
NonCommercial 4.0 International License (http://creativecommons.org/licenses/by-nc/4. $0 /$ ), which permits any noncommercial use, distribution, and reproduction in any medium, provided you give appropriate credit to the original author(s) and the source, provide a link to the Creative Commons license, and indicate if changes were made.

\section{REFERENCES}

1. Antimicrobial Resistance Global Report on Surveillance, 2014. WHO Report. http://www.who. int/drugresistance/documents/AMR_report_Web_ slide_set.pdf?ua=1.

2. Global action plan on antimicrobial resistance Draft resolution with amendments resulting from informal consultations World Health Organization sixty-eighth World Health Assembly 25 May 2015 http://apps.who.int/gb/ebwha/pdf_files/WHA68/ A68_ACONF1Rev1-en.pdf?ua=1. Accessed 12 Aug 2015. 